2012

\title{
Ontario’s Administrative Tribunal Clusters: A Glass Half-Full or Half-Empty for Administrative Justice?
}

Lorne Sossin

Osgoode Hall Law School of York University, lsossin@osgoode.yorku.ca

Jamie Baxter

Follow this and additional works at: http://digitalcommons.osgoode.yorku.ca/all_papers

\section{Repository Citation}

Sossin, Lorne and Baxter, Jamie, "Ontario’s Administrative Tribunal Clusters: A Glass Half-Full or Half-Empty for Administrative Justice?" (2012). All Papers. Paper 28.

http://digitalcommons.osgoode.yorku.ca/all_papers/28 


\title{
Ontario's Administrative Tribunal Clusters: A Glass Half-Full or Half-Empty for Administrative Justice?
}

\author{
Lorne Sossin ${ }^{*}$ \\ Jamie Baxter $^{* *}$
}

February 52012

\footnotetext{
* Dean and Professor, Osgoode Hall Law School, York University

${ }^{* *}$ Visiting Researcher, Faculty of Law, University of Toronto. This author conducted background research for this paper while working as a research assistant at Environment and Land Tribunals Ontario ('ELTO') under the direction of Doug Ewart and Michael Gottheil. He is very much indebted to these individuals for their guidance and insight. None of the commentary, opinions or perspectives in this paper are intended to reflect their views or those of anyone at ELTO, and any errors or omissions are of course the sole responsibility of the authors.
} 


\begin{abstract}
Claimants who come to administrative tribunals in Canada, as elsewhere, expecting a convenient forum to resolve their problems may discover that institutional resources and expertise, their own knowledge of the system, and their statutory entitlements and legal rights are fragmented between agencies with diverse norms and mandates. The provincial government of Ontario in Canada has recently enacted a novel strategy called tribunal clustering to confront these challenges. This paper explores the structure and rationales behind Ontario's new tribunal clusters and compares these with reform models in Australia and the United Kingdom. The authors argue that tribunal clusters offer a flexible approach to institutional change that is responsive to the needs of users and can ultimately improve access and the quality of decision making. In their view, clusters represent a promising first step but not a final destination - to achieve a more effective and coherent system of administrative justice.
\end{abstract}




\section{Contents}

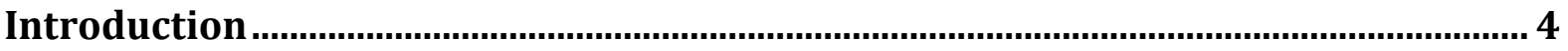

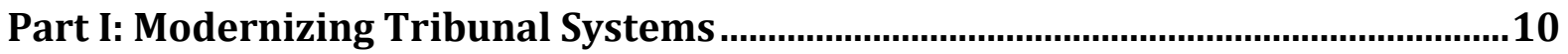

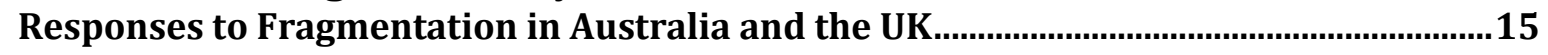

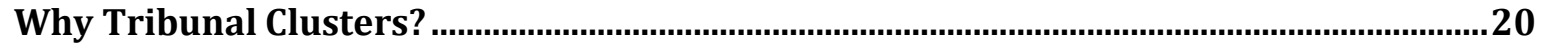

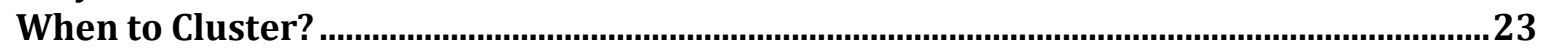

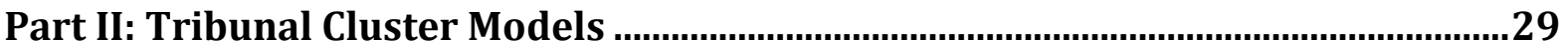

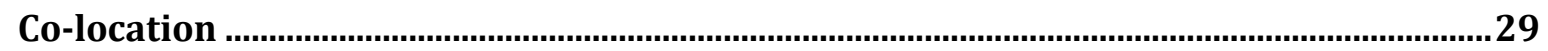

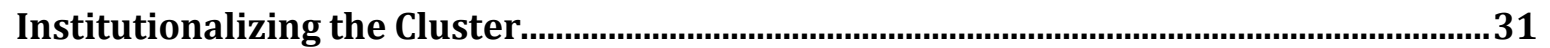

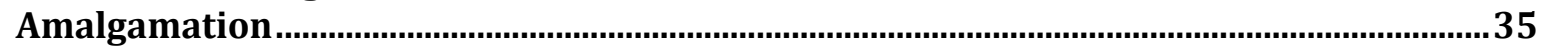

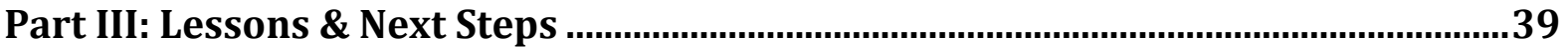

Shared rules, procedures and practices ......................................................................... 41

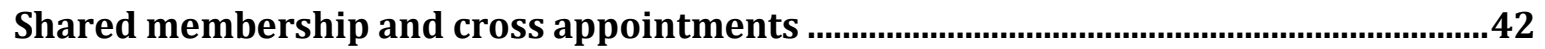

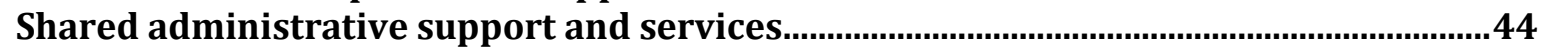

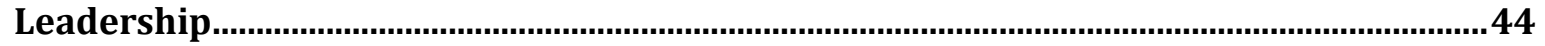

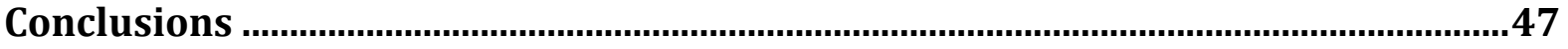




\section{Introduction}

As Peter Cane recently observed, far too little attention in public law has been devoted to administrative justice. ${ }^{1}$ While in some jurisdictions such as the United Kingdom, adjudicative tribunals fall under the supervision of the judiciary, in Canada, the Supreme Court has confirmed that all tribunals, even if their sole task is adjudication, are a part of the executive branch of government, established by statute to further a policy objective. ${ }^{2}$

Governments in Canada continue to experiment with different organizational models in their attempts to balance the policy mandate of tribunals with their adjudicative function, while working to improve accessibility for users and the quality of decision making. By examining the ongoing evolution of tribunal reforms, we believe both the possibilities and limits of administrative justice may be better understood.

The provincial government of Ontario in Canada took a revealing first step to organize its kaleidoscope system of administrative agencies, boards and commissions when it proclaimed the Adjudicative Tribunals Accountability, Governance and Appointments Act (the 'Tribunals Act') in the spring of $2010 .{ }^{3}$ The Tribunals Act proposes a novel strategy for structural reform called tribunal clustering, which groups related tribunals together, but keeps their respective statutory mandates and memberships intact and encourages them to connect along a range of shared characteristics. The resulting cluster organizations aim to capture intersections in tribunals' logistical, procedural, and substantive adjudicatory features and to reinforce links between constituencies of tribunal users.

\footnotetext{
${ }^{1}$ See Peter Cane, Administrative Tribunals and Adjudication (Hart Publishing 2009) and Peter Cane, 'Judicial Review in the Age of Tribunals' (2009) Public Law 479.

2 Ocean Port Hotel Ltd v British Columbia (General Manager, Liquor Control and Licensing Branch), 2001 SCC 52.

3 Adjudicative Tribunals Accountability, Governance and Appointments Act, S.O. 2009, ch. 33, Sched. 5 ('Tribunals Act'). For a discussion of other aspects of this new legislation related to the accountability of tribunals see Laverne Jacobs, 'A Wavering Commitment? Administrative Independence and Collaborative Governance in Ontario’s New Adjudicative Tribunals Accountability Legislation’ (2010) 28(2) Windsor Yearbook of Access to Justice (forthcoming).
} 
These clusters are taking shape at a time when tribunal system restructuring has emerged as a priority in several Commonwealth countries. Compared to recent changes in the United Kingdom and to widespread tribunal amalgamations in Australia at both federal and State levels, Ontario’s clustering model offers a unique strategy for reform - but one for which the long-term vision remains unclear, or at least it appears to be incomplete. In this paper we explore the resulting gaps and uncertainties in this strategy. Using modernization efforts in Australia and the UK as a counterpoint, we argue that Ontario's strategy is founded on a distinctive idea of institutional change designed to make the tribunal system flexible, more adaptive and thus progressively more effective at delivering administrative justice services to its users. That said, tribunal clusters in our view represent an important step but not a final destination.

The need for such change is evident. Claimants who come to administrative tribunals in Canada, as elsewhere, expecting a convenient forum to resolve their problems may discover that institutional resources and expertise, their own knowledge of the system, and their statutory entitlements and legal rights are fragmented between bodies with diverse norms and mandates. At least from a birds-eye view, the tribunal 'system' now looks more like an ad hoc assortment of isolated institutions than a coherent system of justice. Increasingly, it seems that the very structures and modes of organization behind the delivery of administrative justice may actually post barriers for users, even as they separate individual tribunals from the shared knowledge, practices and infrastructure that a more rational and explicitly coordinated administrative justice system would have to offer. The challenge now squarely in front of reformers is to identify suitable approaches to institutional change that will thread these disparate elements into a more coherent whole. 
That challenge is also a reflection of broader trends in the shifting context of modern governance. As Andrew Gamble and Robert Thomas have recently observed in the UK: ${ }^{4}$

Government is certainly not disappearing in the UK or anywhere else, but the context in which governments operate has been transformed, as they grapple with profound challenges arising from globalisation, Europeanisation, the modernisation of the administration and organisation of government, and an evolving constitution. As a result of these changes, governance is becoming more fragmented and diversified, and as a result it is much harder for both politicians and citizens to understand the process of governing.

Ontario shares in the problems that this evolving context raises for the delivery of administrative justice, but the province's response has been distinctive, perhaps unique, compared to strategies enacted elsewhere.

The idea behind tribunal clusters in Ontario traces its origins to the Agency Cluster Project, launched in 2006 with the appointment of Kevin Whittaker (now Justice Whittaker of the Ontario Superior Court of Justice) as facilitator to work with five environmental and land use planning tribunals to explore possibilities for mutual reforms. The project's stated purpose was to identify ways to exploit overlaps between the different tribunals, in order to improve their independence in decision-making, their effectiveness from a user perspective, and their accountability. A key constraint, however, was to achieve these objectives without compromising or collapsing the separate legislative mandates of each constituent tribunal. ${ }^{5}$ Further, there appeared to be little appetite in the province for reforms that would alter the jurisdiction of participant tribunals, and thus the Cluster Project was limited to operate within bounds of existing legislative frameworks.

\footnotetext{
4 Andrew Gamble and Robert Thomas, 'The Changing Context of Governance' in Michael Adler (ed), Administrative Justice in Context (Hart 2010) 6.

${ }^{5}$ Kevin Whitaker, Final Report of the Agency Cluster Facilitator for the Municipal, Environment and Land Planning Tribunals (Minister of Government Services 2007)

<http://www.mgs.gov.on.ca/stdprodconsume/groups/content/@mgs/@aboutmin/documents/resourcelist/166283. pdf $>$ accessed 10 November 2011, 5.
} 
Whittaker's final report introduced the tribunal cluster as 'the grouping together of different tribunals that work in related areas and deal with related subject matter. ${ }^{6}$ The goal of clustering, according to the report, was 'to improve the quality of services offered to the public by sharing resources, expertise and administrative and professional support., ${ }^{7}$ This original vision for tribunal clusters then emerged in the Tribunals Act as a surprisingly openended idea. Section 15 of the Act provides that the province may designate two or more adjudicative tribunals as a cluster if 'the matters that the tribunals deal with are such that they can operate more effectively and efficiently as part of a cluster than alone. ${ }^{8}$ But a detailed description of what a cluster 'is' and specific criteria that describe when it is appropriate to form a cluster are both conspicuously absent from the Tribunals Act. Nor are the rationales behind the cluster concept clarified in the wording of the Act or by nature of the legislative scheme overall. ${ }^{9}$ For these, we find it necessary to look further afield.

Specifically, the austerity of the Tribunals Act as drafted raises a key question going forward: on what basis should individual tribunals be connected within a cluster? In other words, how can we predict when tribunals will operate more ‘effectively' and 'efficiently' as part of a cluster than alone? A more complete answer to this question will be crucial for new cluster organizations as they arise and continue to evolve.

To date, the Tribunals Act has borne two clusters markedly different in composition: Environment and Land Tribunals Ontario ('ELTO’) in April 2010, and Social Justice Tribunals Ontario ('SJTO’) in January $2011 .{ }^{10}$ ELTO brings together five tribunals with overlapping subject matter expertise in land use planning, assessment and expropriation,

\footnotetext{
6 ibid 6.

7 ibid.

8 Tribunals Act (n 3) s 15. For a list of the thirty-seven adjudicative tribunals in Ontario eligible to become part of a cluster see O Reg 126/10, Sched 1.

9 The only additional provisions related to clusters in the Tribunals Act are powers to appoint an executive chair, associate chairs and vice chairs of the cluster, and a specific provision laying out the powers of the executive chair, see Tribunals Act (n 3) ss 16-17.

10 O Reg 126/10, s 2.
} 
heritage conservation, and environmental regulation. SJTO encompasses six tribunals responsible for a diverse range of subject matters but serving a common constituency of users vulnerable to social injustices. Each cluster operates as an independent organization and is led by its own Executive Chair. As we discuss in more detail below, the differences between these two organizations illustrate that the question of when tribunals should form a cluster is one to be answered with reference to the tribunals' existing capacities and to the goals that each particular cluster is trying to achieve.

That question also leads to - and, to some extent, presupposes - a more basic inquiry into the systemic challenges that clusters are designed to confront. Are these clusters in reality just a convenient cost-saving exercise? Certainly, clustering tribunals may give rise to efficiencies. Rather than four payroll offices or four registrars, a cluster of four tribunals may need only one payroll office and one registrar. Everything from renting space to information technology procurement may be more cost effective for larger clustered tribunals than for smaller individual ones. That said, integrating disparate systems and equipment may also give rise to short term costs. The key point, in our view, is not whether clusters are more efficient than individual tribunals operating in isolation but rather, who benefits? If the savings from clustering are reinvested in enhancing the quality of administrative justice, then the beneficiaries will be the tribunals themselves and, more importantly, the parties who come before them. If, however, savings are siphoned off into general revenues, then the clustering exercise would indeed be vulnerable to the critique that it is motivated by fiscal rather and qualitative criteria.

We argue that the cluster concept may present an effective, user-focused strategy to address some of the basic challenges of fragmentation that plague modern systems of administrative justice. Clusters share several elements in common with a trend toward system-wide amalgamation pioneered in Australia and recently adapted in the UK, but 
tribunal clusters also have some unique features of their own. Most significantly, the clustering strategy allows the administrative justice system to retain a certain degree of flexibility and dynamism, with clusters afforded the freedom to develop their own organizational cultures and institutional mandates tailored to the particular needs, demands and capacities of the tribunals' users groups and memberships. The cluster model also motivates tribunals to realize these goals on a continuous basis, rather than locking tribunal organization into a particular pattern that will be unresponsive to the needs of its user populations in the future.

Tribunal clusters have been contemplated in New Zealand and attempted in at least one instance in the United States, but to our knowledge the cluster concept has not yet been defined in any detail nor has it been the subject of a comparative analysis. ${ }^{11}$ We think Ontario’s new Tribunals Act offers a good opportunity to do just that. In Part I of this paper we address the questions of why tribunal clusters might be useful models for reform and when this strategy should be deployed to connect tribunals within a cluster. We begin by reflecting on some of the core challenges that tribunal modernization and reform efforts seek to confront, each of which relate to existing patterns of fragmentation in the delivery of administrative justice. We then connect these patterns to some of the basic rationales behind the clustering strategy, and use this context to assess what Ontario's two new tribunal clusters reveal about the basis for clustering. In Part II we examine the tribunal cluster concept in more depth and canvas the various factors that distinguish this approach from other reform strategies. In Part III, we draw on experiences with tribunal amalgamation in Australia to produce some preliminary insights into various techniques that tribunal clusters might

\footnotetext{
${ }^{11}$ We note that Peter Crane's recent book, Administrative Tribunals and Adjudication (n 1) includes a comprehensive treatment of tribunal systems and structural reforms in Australia, the UK and the United States, but omits a discussion of the experience in Ontario or elsewhere in Canada. Our study contributes to filling that gap.
} 
employ to realize reform goals, and conclude with our view on the continued evolution of the cluster model toward the ultimate destination of administrative justice.

\section{Part I: Modernizing Tribunal Systems}

The goal of modernizing administrative tribunal systems is ultimately to improve access to justice for users. ${ }^{12}$ As the costs associated with traditional court-centred legal processes have grown, so has the popularity of administrative tribunals in the view of both policy makers and various user communities. Individuals are looking to these tribunals as simpler and more economical avenues to review administrative decision making and to resolve their disputes, free from the many formal trappings of the law courts - a trend which is likely to continue as the cost of access grows as a concern, not only for socially and economically disadvantaged individuals but also for the politically significant middle class. ${ }^{13}$

Access to justice is, however, a heterogeneous ideal characterized by at least three different dimensions of accessibility relevant to administrative justice reform. ${ }^{14}$ The first of these is formal access to the tribunal process itself, as determined by agency rules about legal standing to bring claims and by the procedures that govern how a tribunal conducts its hearings. Second, access to legal or other knowledge relates to whether and how individuals will be able to navigate the tribunal system and obtain services from a given tribunal. This type of access is influenced by operational guidelines and policies, a tribunal's use of

\footnotetext{
${ }^{12}$ While we take access to justice as our normative starting point to discuss the modernization of administrative justice systems, we acknowledge that this claim is not without controversy. Others may view the aims of modernizing administrative justice in a different light. For example, following the most recent economic recession in the UK, political discourse surrounding the 'modernization' of employment tribunals in that country appears to focus primarily on streamlining and incentivizing tribunal processes by imposing user fees and deposit orders, and by granting new powers to strike out claims: see Department for Business Innovation \& Skills, Resolving Workplace Disputes: A Consultation (January 2011)

$<$ http://www.bis.gov.uk/assets/biscore/employment-matters/docs/r/11-511-resolving-workplace-disputesconsultation.pdf $>$ accessed 18 January 18 2011, 27. Such reforms would appear, on their face, to embody an approach to modernization motivated by normative concerns quite different from the ones we seek to emphasize in this paper.

13 Michael Trebilcock, Tony Dugan and Lorne Sossin (eds), Middle Income Access to Justice (University of Toronto Press, forthcoming).

${ }^{14}$ For a preliminary discussion of these dimensions of accessibility, see Lorne Sossin, 'Access to Administrative Justice and Other Worries’ in Colleen Flood and Lorne Sossin (eds), Administrative Law in Context (Edmond Montgomery 2008).
} 
language and the availability of translation and assisted services, the ability to self-represent, the simplicity of a tribunal's procedures, and the availability of past decisions to the general public. Third, access to the resources needed to participate in the tribunal system will be a core consideration for many users. The level of resources required for authentic participation in the tribunal system will depend both on the availability of subsidized assistance and on the costs associated with participation, including costs of representation, administration fees, and the rules governing cost awards.

Unfortunately, even while individual administrative tribunals are promoted as simpler, more efficient and more expert in particular subject matters than courts, fragmentation within tribunal systems continues to thwart these basic dimensions of access for users in several ways. ${ }^{15}$ Consider the low-income individual in Ontario who faces a challenge in obtaining social benefits and is in a dispute with her landlord. That individual needs to navigate both the Social Benefits Tribunal and the Landlord Tenant Board's procedures and rules. These two tribunals may operate in separate buildings and use different forms. They may employ different styles of adjudication and they may have divergent or even clashing organizational cultures. As a result, the user is forced to navigate a set of institutional silos which impose high financial and informational costs and likely impede the overall quality of justice services that the tribunals can offer. ${ }^{16}$

The New Zealand Law Commission has reported a 'lack of overall coherence' in many tribunal systems, making individual tribunals increasingly difficult for users to understand and navigate as interrelated institutions, and vulnerable to claims that they fail to

\footnotetext{
15 Many of these challenges are summarized by the New Zealand Law Commission in its report on tribunal reform, see New Zealand Law Commission, Tribunal Reform (New Zealand Law Commission SP 20, 2008) <http://www.lawcom.govt.nz/sites/default/files/publications/2008/12/Publication_131_424_Web\%20TribunalReform-Study-Paper-20.pdf $>$ accessed 20 November 2011, 5-6, 33-36. See also Law Commission of New Zealand, Tribunals in New Zealand (New Zealand Law Commission IP 6, 2008).

${ }^{16}$ Michael Adler has described this approach to reform as being derived from "the perspective of the normative expectations held by members of the public”, see Michael Adler, 'From Tribunal Reform to the Reform of Administrative Justice' in Robin Creyke (ed), Tribunals in the Common Law World (Federation Press 2008) 155.
} 
deliver administrative justice in cost-effective ways. ${ }^{17}$ That conclusion echoes earlier comments by Sir Andrew Leggatt in his review of the UK’s tribunals in 2001: ‘[m]ost tribunals [in the UK] are entirely self-contained, and operate separately from each other, using different practices and standards. It is obvious that the term 'tribunal system' is a misnomer... each tribunal has evolved as a solution to a particular problem, adapted to one particular area.' 18

One obvious outcome of this fragmented landscape is that the sheer number of administrative tribunals - each with their own physical and logistical infrastructure represents a considerable duplication of resources and prevents smaller tribunals from achieving economies of scale. ${ }^{19}$ In a survey preceding its report on tribunal reform, the New Zealand Law Commission counted over 100 specialist tribunals and courts in that country alone, ${ }^{20}$ while Leggatt considered 70 different tribunal bodies within the scope of his review. ${ }^{21}$ Despite opportunities for some tribunals to share their resources many remain operating in isolation, likely in part because each tribunal is or perceives itself to be limited by its enabling legislation and by the associated mandates of a particular government ministry. Likewise, individual tribunals are each responsible for designing and implementing their own practices and procedures, making it difficult for users of more than one tribunal to access knowledge and to operate between them. This can be particularly frustrating for users

\footnotetext{
${ }^{17}$ New Zealand Law Commission, Tribunal Reform (n 15) 6.

${ }^{18}$ Andrew Leggatt, Tribunals for Users: One System, One Service (Stationary Office 2001) para 3.2. We also note Lord Irvine's comments in launching the Leggatt review that "[the] haphazard growth of tribunals, complex routes of appeal, and the need for mechanisms to ensure coherent development of the law" were primary motivators for a widespread review of the country's tribunal system, see Gary Slapper and David Kelly, Sourcebook on the English Legal System (2nd edn, Routledge 2001) 283.

${ }_{19}$ ibid [Overview, para 1] (Andrew Leggatt, Tribunals for Users). See also Hon. Justice J. Bruce Robertson, 'Administering of Justice Without Borders' (Council of Canadian Administrative Tribunals conference, May 2007) <http://www.ccat-ctac.org/downloads/C-16aRobertson.pdf> accessed 20 November 2011, 2.

${ }^{20}$ New Zealand Law Commission, Striking the Balance (NZLC Preliminary Paper 51, 2002) $<$ http://www.lawcom.govt.nz/sites/default/files/publications/2002/05/Publication_89_212_PP51.pdf > accessed 20 November 2011, 51.

${ }^{21}$ Leggatt (n 18) Overview, para 2.
} 
when a single dispute concerns more than one tribunal - for example, where land use, planning and environmental regulatory issues coincide. ${ }^{22}$

On a more basic level, the complexity of tribunal systems may impair public awareness of which tribunals exist in the first place, what these bodies do, and how to go about accessing them. ${ }^{23}$ As the UK government acknowledged in its White Paper responding to the Leggatt review, 'existing systems of redress do not take people’s problems as a whole. Instead they break them down into types and generally insist that people analyse what sort of redress they need and choose the appropriate route. It is rather as if a travel agent insisted on knowing whether you want to go by aeroplane, train or ferry before asking what your destination is. ${ }^{24}$ To the extent that fragmentation impairs the public’s understanding about available options, potential users might never even find their way to the front door. Empirical work by Hazel Genn et al. also suggests that these barriers to knowledge may disproportionately impact users who belong to marginalized groups. ${ }^{25}$

The ad hoc evolution of administrative tribunal systems has likewise created serious discontinuities in how individuals' legal rights are determined and has disrupted the flow of knowledge between adjudicators themselves, 'leading to a lack of consistency and in some

\footnotetext{
${ }^{22}$ One response to this challenge in the land and environment context has been to create specialized land and environment courts and tribunals. For a good overview of developments in this area see George Pring and Catherine Pring, Greening Justice: Creating and Improving Environmental Courts and Tribunals (World Resources Institute 2009) <http://www.accessinitiative.org/sites/default/files/Greening\%20Justice\%20FInal_31399_WRI.pdf> accessed 20 November 2011. See also Bret Birdsong, 'Adjudicating Sustainability: New Zealand's Environment Court' (2002) 211 Ecology Law Quarterly 1; Justice Paul Stein, 'Specialist Environmental Courts: The Land and Environmental Court of New South Wales, Australia’ (2002) 4 Environmental Law Review, 5; and Kenneth Palmer, 'Reflections on the History and Role of the Environment Court in New Zealand" (2010) 27 Environment and Planning Law Journal 69.

${ }^{23}$ Se Hazel Genn, Ben Lever, Lauren Gray, Nigel Balmer and the National Centre for Social Research, Tribunals for Diverse Users (Department for Constitutional Affairs Research Series 1/06, 2006) $<$ http://www.dca.gov.uk/research/2006/01_2006.pdf> accessed 21 November 2011, 98.

${ }^{24}$ Department for Constitutional Affairs, Transforming Public Services: Complaints, Redress and Tribunals (White Paper, Cm 6243, 2004) para 3.3.

${ }^{25}$ See Genn et al, Tribunals for Diverse Users (n 23) 71-74, for a discussion of possible factors underlying barriers to knowledge about tribunals such as minority status, language, age and gender. In general, Genn notes that "Black and Minority Ethnic" groups were less likely to take action to resolve their disputes compared to "White" respondents. See also Hazel Genn, Paths to Justice: What People Do and Think About Going to Law, (Hart 1999); Hazel Genn and Alan Paterson, Paths to Justice Scotland: What Scottish People Do and Think About Going to Law, (Hart 2001).
} 
cases arbitrary decision-making., ${ }^{26}$ Training standards for tribunal members currently vary widely between different agencies, leading to inconsistent opportunities for members to engage in professional development and learning. In both procedural and substantive dimensions, the current landscape of public administration also makes it difficult for adjudicators with different but interrelated areas of expertise to interact and develop common understandings and approaches. Combating fragmentation is therefore about more than maximizing the efficiencies of resource use; it is also fundamentally about improving the quality and consistency of review to fulfill the guiding principle of procedural fairness.

Fragmentation similarly hinders first-instance decision-makers from learning more effectively from the decisions of review tribunals. A more coherent system would improve the quality of first-instance decisions by facilitating better feedback processes from tribunal adjudication, allowing judgments from all related tribunals to inform administrative decision making in the future. Certainly, some authors have questioned whether appeal decisions issued by tribunals have traditionally had much effect on the quality of first-instance decision making. ${ }^{27}$ Addressing the problems associated with fragmentation in the tribunal system may be one response to this disconnect. Over time, a system that fosters better first-instance decisions will tend to rely less on appeals or judicial review, enhancing access to justice by lowering costs and the time required to achieve a just outcome. Moreover, fragmentation in determining legal rights likely makes it more difficult for tribunals to maintain decisionmaking independence from their respective ministries. A system of atomized tribunal bodies operating in relative isolation likely creates more opportunities for departmental capture and

\footnotetext{
${ }^{26}$ Robin Creyke, 'Tribunals: Divergence and Loss' (2001) 29 Federal Law Review 403, 409 (quoting the Minister introducing the Bill for the ADT).

${ }^{27}$ See Michael Adler, 'Understanding and Analyzing Administrative Justice’ in Michael Adler (ed), Administrative Justice in Context (Hart 2010)145 [citing as support an empirical study of social security tribunals in the UK, John Baldwin, Nicholas Wikeley and Richard Young, Judging Social Security: The Adjudication of Claims for Benefit in Britain (Clarendon Press 1992)].
} 
makes it difficult to impose and regulate the shared principles of transparency and openness that can flow from greater independence.

\section{Responses to Fragmentation in Australia and the UK}

Australia and the UK, as two large common law jurisdictions with a shared history of administrative state expansion following the Second World War provide helpful comparative insights with respect to contemporary reforms in administrative justice.

System-wide reform efforts in these countries have attempted to address the various aspects of fragmentation that plague modern administrative states. The earliest of these initiatives was to establish the federal Administrative Appeals Tribunal (AAT) in Australia in 1976 following a pioneering report by the Commonwealth Administrative Review

Committee chaired by Sir John Kerr. ${ }^{28}$ At that time, the Kerr Committee sketched a picture of an administrative justice system that was uncoordinated, contained many gaps, and was not easily understood by its constituents. ${ }^{29}$ The ultimate product of the Committee's report, the Administrative Tribunals Act, created a generalist tribunal to review administrative decisions which today has jurisdiction to conduct merits review under a wide variety of more than 400 Acts of the federal Parliament. ${ }^{30}$

The AAT also exercises an appellate function with respect to the decisions of a few remaining specialist tribunals in the areas of social security and veterans' benefits. ${ }^{31}$ In 1995 , Australia's Administrative Research Council recommended that the federal government create a new two-tier Administrative Review Tribunal (ART) to replace the AAT, providing for an internal appellate structure and further integration of the remaining independent

\footnotetext{
28 Commonwealth Administrative Review Committee, Report (CARC PP No 144, 1971).

29 Administrative Review Council, Overview of the Commonwealth System of Administrative Review (Department of the Attorney General 2011) <http://www.ema.gov.au/agd/WWW/archome.nsf/Page/Overview_Overview_of_the_Commonwealth_System_ of_Admin_Review> accessed 21 November 2011, para 26.

${ }^{30}$ Lord Carnwath et al, 'An Overview of the Tribunal Scenes in Australia, Canada, New Zealand and the UK' in Robin Creyke (ed), Tribunals in the Common Law World (Federation Press 2008) 3.

${ }^{31}$ Crane, Administrative Tribunals (n 1) 117-118.
} 
tribunals. Although the government accepted this proposal in principle, resistance to the idea ultimately defeated legislation in 2003 that would have realized the reforms. ${ }^{32}$

While a small number of specialist federal tribunals still exist in Australia, the outcome of the AAT model has been to centralize merits review of first-instance decisions within a single organization that includes a membership of appointed judges, lawyers, and experts in various fields such as medical practitioners, engineers and planners. This "super tribunal" model has been replicated at the State level in Australia, although these tribunals have taken on a variety of different forms in practice. The jurisdiction of the Victoria Civil and Administrative Tribunal (VCAT) extends beyond merits review into human rights and some civil claims. The VCAT's organizational structure appears to be somewhat more nuanced compared to the AAT, and we draw several parallels between VCAT's model and that of tribunal clusters in Ontario later in this paper. Western Australia's State Administrative Tribunal was not established until 2004, but closely tracks the structure of the VCAT. ${ }^{33}$ Jurisdiction over merits review and dispute settlement in New South Wales remains more fragmented compared to Victoria and Western Australia, although the State's Administrative Decisions Tribunal (ADT), established in 1997, was designed to act as an amalgamated generalist review body. Some of the differences between the VCAT and ADT models are discussed in more detail in Part III, below.

Tribunal system reforms have also received considerable attention in the UK, motivated most recently by Sir Andrew Leggatt’s review of the tribunal system in $2001 .^{34}$ The Leggatt Report recommended that tribunals in the UK be collected together under one

\footnotetext{
32 Administrative Research Council, Better Decisions: Review of Commonwealth Merits Review Tribunals (ARC Report No 39, 1995). See also ibid 64-67.

33 Carnwath et al (n 30) 5.

34 Leggatt (n 18). See also Sir Robert Carnwath, ‘Administrative Justice-A Quiet Revolution’ (2008) 30 Journal of Social Welfare and Family Law 283; Edwards Jacobs, 'Something Old, Something New: The New Tribunal System' (2009) 38 Industrial Law Journal 417; Sir Robert Carnwath, 'Tribunal Justice - A New Start' (2009) 1 Public Law 48.
} 
umbrella and administered by a new agency reporting to the Lord Chancellor. ${ }^{35}$ That report received a favourable response from the government in its 2004 White Paper. ${ }^{36}$ The White Paper addressed several core concerns raised by Leggatt, including the physical accessibility of tribunal locations, access to process and knowledge, the independence of tribunals from their sponsoring departments and the overall quality of decision-making. The government also noted that some of the barriers inhibiting reform were rooted in current patterns of organization within the system itself and observed that 'present arrangements are highly fragmented, with each department, agency or tribunal responsible for trying to make improvements within its own sphere of operation., ${ }^{37}$

These concerns proved serious enough to motivate political intervention and broad structural change. The UK Tribunals Service was established as an 'Executive Agency’ in April 2006, and the Tribunals, Courts and Enforcement Act 2007 (TCEA) was enacted the following year, creating a single, unified agency with a two-tiered structure beginning in November 2008. ${ }^{38}$ To lead this new agency, the TCEA provides for a Senior President of the Tribunal Judiciary charged with taking account of the need for tribunals to be accessible, fair, quick, efficient, expert in their subject matter, and innovative in developing methods to resolve disputes. ${ }^{39}$ Most recently, in 2011, the Tribunals Service joined with the Courts Service to form Her Majesty’s Courts and Tribunals Service (“HMCTS”). This body operates under a Framework Agreement between the Lord Chancellor, the Lord Chief Justice and the Senior President of Tribunals to support the administration of both courts and tribunals in the country. $^{40}$

\footnotetext{
35 Carnwath et al (n 30) 21.

36 Department for Constitutional Affairs (n 24).

${ }^{37}$ Department for Constitutional Affairs (n 24) 25.

38 Tribunals, Courts and Enforcement Act 2007 (UK); Lord Justice Carnwath, 'Tribunals and the Courts - the UK Model' (2011) 24 Canadian Journal of Administrative Law and Practice 6.

${ }^{39}$ Ibid s 2. Lord Justice Carnwath was appointed as the agency’s first Senior President in November 2007.

${ }^{40}$ Lord Chancellor and Secretary of State for Justice, Her Majesty’s Courts and Tribunals Service Framework Document (Cm 8043, April 2011).
} 
The two amalgamated tribunal bodies created under the TCEA parallel the Australian reforms in the mid-1970s and subsequent refinements of that model at the State level, although its two-tier structure appears to be unique in some respects. The new First-tier Tribunal of HMCTS conducts first instance review of the decisions of public administrators. It has acquired the jurisdiction of the bulk of administrative tribunals in the UK, with the notable exception of the system of planning appeals, which remains a distinct process. ${ }^{41}$ The Upper Tribunal was established to rationalize the 'haphazard' network of appeal routes from first instance tribunals under the old system, ${ }^{42}$ and also exercises statutory jurisdiction to conduct judicial review. Each of these two tribunals retain a degree of specialization within different 'Chambers', though judges and tribunal members can be cross-appointed between these divisions. The First-tier Tribunal consists of seven different chambers - Social Entitlement; Immigration and Asylum; Health, Education and Social Care; War Pensions and Armed Forces Compensation; Tax; General Regulatory; and Land, Property and Housing with each having a Chamber President appointed by the Judicial Appointments Commission. The Upper Tribunal has four chambers: Administrative Appeals; Immigration and Asylum; Tax and Chancery; and Land. The Upper Tier's Chamber Presidents, other than that of the Land Chamber, are appointed by the Lord Chief Justice. ${ }^{43}$

In practice, Peter Crane observes that the new organization of tribunal adjudication in the UK most closely reflects the two-tiered model proposed by Australia's Administrative Research Council in the mid-1990s but later abandoned by the Australian government. ${ }^{44}$ The outcome for the UK, Crane argues, is a system not unlike that of conventional law courts. Australia - at least at the federal level - has so far resisted this trajectory in favour of model that sees amalgamated tribunal agencies as a "distinct genus of adjudicatory institution" that

\footnotetext{
${ }^{41}$ Peter Cane, Administrative Law, 5th ed (Oxford University Press 2011) 317.

42 Carnwath et al (n 30) 25.

${ }^{43}$ Carnwath, 'Tribunals and the Courts' (n 38) 7.

${ }^{44}$ Crane, Administrative Tribunals (n 1) 122.
} 
seek to maintain their pragmatic advantages in terms of speed, affordability and informality. ${ }^{45}$

At root, each of these responses can be understood as attempts to re-imagine individual tribunals as part of a coherent and continuous system of administrative justice. That perspective has taken some time to catch hold in Canada. According to Heather McNaughton, '[i]t was not until recently that governments and Canadian courts have started to conceptualise administrative tribunals dealing with such disparate interests as the protection of fundamental human rights, the issuance and transfer of quota for production of agricultural products, and property tax assessment, as being part of a system of justice. ${ }^{46}$ One of the authors has traced this emerging view of administrative justice in Canada's Supreme Court's jurisprudence, and the place of administrative decision-makers within Canada's constitutional order. ${ }^{47}$ Michael Adler has labeled this an 'administrative justice approach' which recognizes the important role of courts, tribunals, ombudsmen and other external redress mechanisms but also emphasizes internal means of enhancing administrative decisions such as recruitment, training and appraisal processes, as well as standard setting and quality assurance systems. ${ }^{48}$

That perspective represents a common thread among administrative justice reforms in several jurisdictions internationally. In its White Paper, the UK government acknowledged that 'the sphere of administrative justice...embraces not just courts and tribunals but the millions of decisions taken by thousands of civil servants and other officials. ${ }^{49}$ Tribunal

\footnotetext{
45 ibid 85.

${ }^{46}$ Heather MacNaughton, 'Future Directions for Administrative Tribunals: Canadian Administrative Justice Where do we go from Here?' in Robin Creyke (ed), Tribunals in the Common Law World (Federation Press 2008) 205.

${ }^{47}$ See Lorne Sossin, 'The Ambivalence of Administrative Justice in Canada: Does Canada Need a Fourth Branch?’ in Adam Dodek and Daniel Jutras (eds), Lamer: The Sacred Fire (LexisNexis 2009) 51. Clustering may advance this project in one respect (as it reflects and reinforces systemic approaches to justice) while complicating it in others (the Social Justice cluster, for example, includes some tribunals that have jurisdiction to hear and adjudicate the Charter of Rights and some that do not, suggesting a lack of coherence).

${ }^{48}$ Adler (n 27) 154.

49 Department for Constitutional Affairs (n24) para 1.6.
} 
reforms should, according to this view, concentrate on more than the final stage of dispute resolution, they should take into account the entire process 'from the initial decision onwards. $^{, 50}$

A countervailing consideration to whole system reform is that administrative tribunals must retain a degree of flexibility in order to accommodate and support their particular mandates and areas of expertise. McNaughton cautions that '[t]he temptation to one size fits all reforms fails to take into account the fact that the specialist areas delegated to administrative tribunals form the very basis for their existence in the first place. ${ }^{51}$ The main challenge of tribunal reform might thus be seen as an attempt to modernize and rationalize administrative tribunal systems while respecting, maintaining and promoting core principles of accessibility, pragmatism, and expediency. The key is to make the system coherent while keeping it 'nimble'. 52

\section{Why Tribunal Clusters?}

The need to strike a balance between system coherence and flexibility speaks to what is probably the tribunal cluster's greatest promise as an 'alternative' strategy for administrative justice reform. In 2008, the New Zealand Law Commission produced a comprehensive report that evaluated tribunal clusters as one of six possible options for reorganizing administrative tribunals at the national level. The Commission's starting point to define tribunal clusters was to emphasize their ability to adapt to changing circumstances: ${ }^{53}$

50 Carnwath, ‘Administrative Justice’ (n 34) 284-85.

51 MacNaughton (n 46). See also Patricia McConnell, 'The Future of Tribunals in New Zealand' in Robin Creyke (ed), Tribunals in the Common Law World (Federation Press 2008) 198 ("Administrative tidiness must not be preferred to tribunals' ability to do substantive justice in individual cases. Different clusters of tribunals, or lists within a unified structure, should not necessarily have identical processes and procedures”).

52 Judith McCormack, 'Nimble Justice: Revitalizing Administrative Tribunals in a Climate of Rapid Change’ (1995) 59 Saskatchewan Law Review 385.

53 New Zealand Law Commission, Tribunal Reform (n 15) 54-55. The New Zealand Law Commission and the Ministry of Justice commenced their project to advance a program for tribunal reform in November 2006. The purpose of this project was to survey the landscape of New Zealand's existing tribunals and to make recommendations on structural reform for existing tribunals and for establishing new tribunals in the future. In its latest report of October 2008, the Law Commission explores several models for reform and makes some initial recommendations as to its preferred option of a unified tribunal service. 
[T]here is no abstract definition of the concept of a cluster. The idea of a cluster does not compel any particular level of integration or sharing of services... Rather, the cluster model can be designed in a nuanced way, reflecting the level of connectedness that is desired for each different cluster. We stress too that the extent of connection need not be the same for each cluster within the reform. There may, for example, be one cluster where the tribunals are closely connected in terms of common membership and procedures. This cluster may even merge some of the individual tribunals' jurisdictions. On the other hand, another cluster could be a far looser grouping, with individual tribunals maintaining their own identities, sharing fewer members and having greater procedural variance among themselves.

The Commission appeared to view the cluster concept as a central organizing idea capable of accommodating the various functional objectives of reformers and the differing capacities of constituent tribunals. The Commission also saw that tribunal clusters should be principally designed to reinforce connections between existing tribunals based on their respective strengths and advantages. This search to identify and support the successful aspects of existing tribunals - rather than exclusively targeting current problems or shortfalls - is a significant departure from the conventional wisdom that administrative tribunal reforms should mainly be focused on wiping away the system's chaotic past and starting with an entirely clean slate. ${ }^{54}$

On this view, what sets tribunal clusters apart from other strategies is that they are functionally designed to create the conditions for setting standards of excellence, improving the relationship between user groups, streamlining tribunal administration, and crosspollinating approaches to adjudication across different areas of expertise. The more interesting question is therefore not 'why tribunal clusters?' but rather 'why clusters and not simply "super-tribunals” like the AAT and VCAT in Australia or an integrated Tribunal Service as in the UK?' In other words, if bigger is better, why take the half measure of creating a cluster? In our view, there are three important reasons why clusters make sense

\footnotetext{
${ }^{54}$ Although it considered the clustering model, the New Zealand Law Commission ultimately recommended a 'unified tribunal structure' that includes specialized divisions and further sub-groupings to retain some flexibility within the amalgamated structure.
} 
compared to strategies in Australia and the UK. First, bigger may not always be better.

Clusters allow tribunals, government and independent reviewers and academics alike to put that proposition to the test. For example, large-scale amalgamations may trade off flexibility and adaptability within the super-tribunal in return for greater conformity across the organization. Second, clusters allow for learning across and between tribunals. Tribunals previously in relationships with separate ministries can, in one cluster, highlight the best practices and procedures from each in order to give the cluster a distinct identity. ${ }^{55}$

Third, the structure of tribunal clusters may accurately reflects how users actually experience justice problems in some circumstances. National civil legal needs surveys conducted in several countries over the past decade have confirmed that recognizable patterns emerge in the ways that individuals experience multiple issues. ${ }^{56}$ The surveys reveal that specific problems tend to cluster together - meaning that, for example, an individual who experiences a housing problem would be more likely to also encounter challenges related disability benefits. ${ }^{57}$ Tribunals will adjudicate many of these clustered subject matters. These survey data suggest that tribunal systems might be more effective at addressing administrative justice problems if they are structured to reflect the underlying needs of their users. Tribunal clusters offer one means of moving toward this outcome.

\footnotetext{
${ }^{55}$ Under Ontario's Tribunals Act, tribunals within a cluster must also jointly develop governance and accountability documents, reinforcing that each tribunal has its own "identity and purpose", see Michael Gottheil and Doug Ewart, 'Lessons from ELTO: The Potential of Ontario's Clustering Model to Advance Administrative Justice’ (2011) 24(2) Canadian Journal of Administrative Law and Practice 161, 166.

${ }^{56}$ For a comparative overview of these surveys see Jamie Baxter, Michael Trebilcock and Albert Yoon, 'The Ontario Civil Legal Needs Project: A Comparative Analysis of the 2009 Survey Data' in Michael Trebilcock Anthony Duggan and Lorne Sossin (eds), Middle Income Access to Justice (n 13).

${ }^{57}$ See for example, Pascoe Pleasence et al, Causes of Action: Civil Law and Social Justice (Legal Services Commission 2004) 39-40 <http://www.justice.gov.uk/downloads/publications/research-andanalysis/lsrc/Causes\%20of\%20Action.pdf > accessed November 21, 2011; Ab Currie, The Legal Problems of Everyday Life: The Nature, Extent and Consequences of Justiciable Problems Experienced by Canadians (Department of Justice Canada 2007) $42<$ http://justice-canada.net/eng/pi/rs/rep-rap/2007/rr07_la1rr07_aj1/rr07_la1.pdf> accessed 21 November 2011; Christine Coumarelos, Zhigang Wei, and Albert Zhou, Justice Made to Measure: NSW Legal Needs Survey in Disadvantaged Areas (Law and Justice Foundation of New South Wales 2006) 75 $<$ http://www.lawfoundation.net.au/ljf/site/articleIDs/B9662F72F04ECB17CA25713E001D6BBA/\$file/Justice_ Made_to_Measure.pdf > accessed 21 November 2011.
} 
That said, in our view, tribunal clusters are not a final destination for administrative justice reform; rather, they are a means for arriving at a more rational and coherent way of delivering administrative justice. This fluidity is, moreover, exactly what many tribunal systems may require to help them meet the complex challenges of fragmentation discussed above. Tribunal clusters are motivated by the idea that systemic reforms should concentrate on working out the most coherent system, in practice, on an ongoing basis.

While some might regard their open-endedness as a liability for new clusters, others will see this as an inherent strength of the clustering model. By requiring the decision-makers who are responsible for defining each cluster to confront the extant features of the group's constituent tribunals, the cluster concept challenges leadership within the system to focus on areas for change or reform, but also on the strengths and best practices that have been developed by each tribunal in the past. A core tension within tribunal clusters is, and will likely continue to be, between recognizing the separate statutory mandates of each constituent tribunal on the one hand and encouraging deeper substantive and procedural integration on the other. There is no doubt that the structural and organizational redesign of tribunals in the absence of substantive legislative reform represents one of the biggest challenges for cluster models. But placing too much emphasis on this tension is likely to detract from more pertinent questions: What areas of knowledge from each tribunal—substantive, normative, procedural—should be nourished and promoted across the cluster with reference to improving access to justice, what features of individual tribunals ought to be left unchanged, and what aspects are good targets for institutional reform? This approach is rooted in the notion that tribunals will bring valuable institutional knowledge that is worth being preserved and shared within the cluster, as well as challenges and problems in need of reform.

\section{When to Cluster?}


Our conceptual starting point leads back to the question of when and on what basis it will be appropriate to group existing tribunals together within a cluster. Recall that Ontario’s Tribunals Act authorizes the province to designate two or more adjudicative tribunals as a cluster if 'the matters that the tribunals deal with are such that they can operate more effectively and efficiently as part of a cluster than alone. ${ }^{58}$ Does this reference to the "matters that the tribunals deal with' suggest that each tribunal's core jurisdiction should be a central focus when designating a cluster? Whitaker's original Agency Cluster Project report seems to reinforce this interpretation, suggesting that clustered tribunals should work in related areas and deal with related subject matter. ${ }^{59}$ But read in context of the pragmatic rationales that underpin clustering and its inherent flexibility as a reform strategy, a more expansive interpretation of the Tribunals Act seems warranted.

Taken as a whole, these rationales imply that the overriding orientation of clustering should be instrumental rather than formalistic - that is, tribunals should be clustered whenever it is 'efficient' and 'effective' to do so. Such an instrumental approach no doubt requires policy makers to consider the subject matter of constituent tribunals in some cases, but also points to the character of tribunals' user communities and to procedural, adjudicatory or administrative similarities as equally significant factors in deciding when it is appropriate to form a tribunal cluster. ${ }^{60}$ This approach also raises the interesting question of when it would not be efficient and effective for tribunals to cluster. One answer may be where a tribunal itself is already the product of amalgamation and so enjoys many of the benefits of clustering (for example, the Ontario Financial Services Tribunal was created through merging smaller tribunals responsible for pensions and insurance, while the Ontario License Appeals Tribunal similarly arose through an amalgamation of smaller licensing tribunals).

\footnotetext{
58 Tribunals Act (n 3) s 15.

59 Whitaker (n 5).

${ }^{60}$ Gottheil and Ewart (n 55) 165.
} 
The two tribunal clusters formed under the Tribunals Act to date tend to support our instrumental interpretation of the Act, and the particular foundation of each cluster appears like to vary depending on the circumstances in and goals for which each cluster is formed. Environment and Land Tribunals Ontario ('ELTO’) was the province's first tribunal cluster, formally minted in April 2010 out of the five participant tribunals in the Agency Cluster Project: the Assessment Review Board, which deals with property tax assessment and tax appeals, the Board of Negotiation, which provides mediation in compensation disputes arising from land expropriations, the Conservation Review Board, which adjudicates disputes concerning designated heritage status properties and archaeological sites, the Environmental Review Tribunals, which handles a range of environmental disputes, and the Ontario Municipal Board, which hears appeals and applications on a wide range of municipal, planning and land-related matters. Following the Cluster Project and before the Tribunals Act was enacted, these tribunals were co-located in a common physical space and began to integrate some aspects of their administrative operations. ELTO’s formal designation as a cluster followed the appointment of an Executive Chair, who is also a cross-appointed member of each tribunal in the cluster, in November 2009 and the passage of the Tribunals Act that Fall. ${ }^{61}$

ELTO's tribunals deal with closely connected subject matters in the land and environment areas - two domains that increasingly overlap as regimes of environmental planning, conservation, and land use zoning control have become prominent features of Ontario's regulatory landscape. ${ }^{62}$ ELTO's user communities, on the other hand, are very

\footnotetext{
${ }^{61}$ See Gottheil and Ewart (n 55) for a discussion of ELTO’s early experiences with the clustering model. We rely on a number of insights from Gottheil and Ewart's paper in this section.

${ }^{62}$ For example, see Edward Canuel, 'Supporting Smart Growth Legislation and Audits: An Analysis of US and Canadian Land Planning Theories and Tools' (2005) 13 Mich St J Int'l L 309 (for a overview of 'smart growth' strategies as a development approach that attempts to balance economic progress with environmental protection]. For experiences in Australia see John Horwich, 'Environmental Planning: Lessons from New South Wales, Australia in the Integration of Land-Use Planning and Environmental Protection' (1997) 17 Virginia Environmental Law Journal 267.
} 
likely to be highly segmented, and in some instances its user groups represent directly competing interests. Indeed, environmental regulators and conservation groups have frequently clashed with land developers over a range of concerns on the contested terrain of "sustainable development". This concept provides a prominent example of one subject matter that cuts across most if not all of ELTO's tribunals.

In a recent article, Michael Gottheil, former Executive Chair of ELTO, and Doug Ewart, ELTO’s Senior Advisor, indicate that a key focus in the new cluster has been to reinforce connections between the tribunals' subject matters and contexts, and to promote the sharing of knowledge, experience and perspectives between constituent tribunals. ${ }^{63}$ ELTO is a good example of a cluster where the nature of the tribunals and their respective mandates offer good possibilities for innovations that improve the quality and consistency of decisionmaking on merits review, leading to better outcomes for tribunal users.

A second set of six Ontario tribunals was recently brought together as part of Social Justice Tribunals Ontario ("SJTO") in January 2011. This cluster includes the Human Rights Tribunal of Ontario, the Child and Family Services Review Board, the Custody Review Board, the Social Benefits Tribunal/Social Assistance Review Board, the Special Education Tribunals (English and French) and the Landlord and Tenant Board. In comparison to ELTO, SJTO's tribunals deal with a much more diverse range of subject matters and most share little in the way of substantive overlap, although some, such as the Custody Review and Child and Family Review Boards, will likely cultivate important subject matter connections. ${ }^{64}$ As the SJTO's name itself suggests, a primary motivation behind its formation has been to create a "single door" institution for a shared community of users vulnerable to social injustice from a range of causes such as discrimination, physical and mental disabilities and economic

\footnotetext{
${ }^{63}$ Gottheil and Ewart (n 55) 170.

${ }^{64}$ In 1999, a part-time Chair was appointed to lead the two Boards and part-time members were cross-appointed to both Boards. In 2006, prior to the formation of SJTO, a full-time Chair and two Vice Chairs were appointed to both boards.
} 
disadvantage. The SJTO tribunals thus appear to have clustered around the socio-economic characteristics and other identifying features of users, rather than the particular subject matters dealt with by the tribunals.

Ontario’s two existing tribunal clusters indicate that the functional criteria of efficiency and effectiveness will likely have different reference points depending on the circumstances in which the cluster is formed. ELTO's experience reveals that subject matter jurisdiction will be central in some instances, while the new SJTO suggests that common characteristics of the cluster's user communities will be a main focus in others.

The New Zealand Law Commission has suggested that reformers should also pay attention to the nature of tribunals' adjudicatory powers when contemplating how to group like tribunal together. ${ }^{65}$ The Commission noted that the core function of some tribunals is to review government decision-making, and distinguished these from other bodies dealing with inter parts disputes.

The Commission's study was careful to observe that the aspirations of each tribunal cluster, as well as the challenges it seeks to address, should shape how that cluster is designed. It also underscored the contested implications of 'expertise'. Administrative lawyers frequently refer to the expertise of adjudicators in a particular field of knowledge, but rarely acknowledge expertise in certain procedures or techniques. One can imagine situations in which members' specialized knowledge of subject areas converge (perhaps members from different tribunals all have a similar background in land use planning), pulling toward a common set of procedures and practices that would encourage cross-fertilization between tribunals. But these same members’ expertise in specific forms of dispute-resolution processes might diverge considerably, favouring more distinct procedural rules for each tribunal within the cluster. Alternatively, the form of dispute-resolution itself, such as an

65 New Zealand Law Commission, Tribunal Reform (n 15) 55-56. 
emphasis on inquisitorial processes or ADR techniques, rather than an adversarial approach, could stand as yet another basis for organizing tribunals into cluster. 


\section{Part II: Tribunal Cluster Models}

Having outlined the basic motivations behind the tribunal cluster model, we next describe the actual structure of tribunal clusters in their various forms. It is useful to situate cluster-type arrangements along a spectrum that ranges from basic physical co-location of like tribunals, to tribunal clusters, to fully integrated tribunal amalgamation. In reality, actual tribunal clusters will tend not to occupy a specific point along this spectrum, but will likely mix and match some features of each approach to create context-specific arrangements.

\section{Co-location}

The most basic type of structural reform related to tribunal clusters is the co-location model, whereby tribunals are brought together to share the same physical space and perhaps some overlapping logistical infrastructure. This model normally entails a 'single door' approach that allows users of the co-located tribunals to attend at a single location and gain information about the various procedures from constituent tribunals. On the back-end, colocated tribunals will generally each retain leadership and control over their own affairs, although some efficiencies in administrative collaboration may be available. Given that colocation is basically about logistical re-organization, this strategy can likely be employed without the need for new legislation authorizing the structure. The statutory mandate and membership of each co-located tribunal in this model remains separate form those of other participating tribunals.

In Australia, Robin Creyke has noted both the possibilities and limitations inherent in this approach: ${ }^{66}$

The advantages of the co-location model are that it preserves the status quo, retains the flexibility of a variety of specialist bodies, while permitting cost savings from use of a common registry and administrative infrastructure. The disadvantages are that it perpetuates the complexity and lack of coherence of the system, does not permit

\footnotetext{
66 Robin Creyke, ‘Tribunals and Access to Justice’' (2002) 2 Queensland University of Technology Law and Justice Journal 64, 72.
} 
further savings other than those involved in co-location, and enhances the possibility of tribunal capture by its respective agency. This first option also denies the possibility for development of an administrative law jurisprudence across tribunals on matters of common interest, such as, for example, the failure to notify citizens of decisions, the minimum content of statements of reasons, the circumstances in which tribunals can revisit their decisions, and when tribunals are estopped from acting.

Creyke's assumptions about the limitations of a bare co-location model may hold in circumstances where there is little motivation to cultivate further connections between tribunals, but her analysis appears to be overly pessimistic about opportunities for procedural and substantive innovations insofar as they are applicable to clusters more generally. Creyke’s assessment may also gloss over some of the important nuances that can be built into co-location as one aspect of clustering. For example, considerations such as office geography, discussed below, can yield important influences on the ability to share knowledge and practices between tribunals.

While co-located tribunals lack some of the more sophisticated organizational components granted to fully-fledged tribunal clusters, this model may represent a valuable starting point for further reforms within and between participant tribunals. Indeed, prior to the enactment of the Tribunals Act in Ontario, the five tribunals that later formed Environment and Land Tribunals Ontario began the clustering process by co-locating before becoming a cluster authorized under the new Act. Co-location may be particularly relevant in the Canadian context where sole tribunals face significant hurdles to provide adjudication outside of major urban areas. Co-located tribunals could have economies of scale to offer adjudication in a wider number of centres, or invest in better technology for remote access (video-conferencing, etc) than sole tribunals.

It will come as no surprise that physical co-location of tribunals is likely to be a central feature of most tribunal cluster arrangements. But research from Australia has gone further, to investigate the significance of designing the physical space within which 
constituent tribunals are situated. Insights in this area often seem to flow from basic common sense, but have apparently had an immediate impact on achieving the objectives of tribunal reform in Australia.

In her research work on this topic, Rachel Bacon emphasizes the importance of shared spaces within the office environment, especially those in which the membership can interact on a daily basis. ${ }^{67}$ This was a central design feature of the Victorian Civil and Administrative Tribunal's (VCAT) new premises when they were designed for this new body. VCAT's leadership made a conscious choice to "mix up” the office spaces of members from the former specialist tribunals, with the expectation that this would contribute to breaking down cultural barriers. A similar strategy appears to be underway at ELTO, where adjudicators from all of the cluster's tribunals have their offices on the same floor. This arrangement encourages informal conversation and knowledge sharing between adjudicators from different tribunals. $^{68}$

Virtual co-location is also likely to be significant. This includes both public websites that provide a single point of information access (even where the physical locations of constituent tribunals remain separate) as well as internal electronic information exchange and intranet sites that facilitate communication between tribunals.

\section{Institutionalizing the Cluster}

As with co-location, each tribunal brings to a cluster its distinctive statutory and/or policy mandate. But what sets clusters apart from bare co-location is the broader organizational umbrella that cuts across these jurisdictional divides and encompasses all tribunals within the group. Each tribunal cluster is an institution in its own right, with a shared leadership and administrative staff, memberships of adjudicators, and constituencies

\footnotetext{
${ }^{67}$ Rachel Bacon, Amalgamating Tribunals: A Recipe for Optimal Reform (DPhil thesis, University of Sydney 2004), 289-290.

${ }^{68}$ Gottheil and Ewart (n 55) 9.
} 
of users that are connected or overlap in identifiable ways. The cluster model offers the unique opportunity for these organizations to develop their own culture and adapt this to the particular needs and demands of their users over time.

Tribunal clusters may be characterized by differing levels of complexity in each of these elements. Simpler clusters may operate as relatively horizontal organizations under a single Executive Chair, without additional sub-groupings of related tribunals. These clusters will likely occupy a single location and have a single set of shared procedures. Simple clusters will inevitably prove to be the most straightforward to establish and administer, with minimal disruption of existing tribunals who form part of the cluster. More complex clusters might contain additional layers or higher-order levels of organization as a way of variably defining the cluster's connections according to sub-groupings. For example, tribunals within a sub-group at one level may share related subject-matter jurisdictions, while that sub-group as a whole might share adjudicatory techniques with other sub-groups in the cluster.

Alternatively, levels within a nested cluster might represent increasing areas of generality in subject-matter jurisdiction—for example, between environmental matters at one level and between environment and land-use matters at another. This type of model raises questions about trade-offs between greater organizational complexity and the ability to define subgroups to create a more fine-grained structure. These sub-groupings may make the process of drawing connections between tribunals more straightforward and coherent, given that the needs and functions of some tribunals will fit more or less comfortably with each of the others in the cluster. However, greater complexity will invariably make the cluster more challenging to lead and administer, may increase cost, and may pose a risk to a unified organization insofar as sub-groupings create the possibility to form sub-cultures that entrench old ways of doing things rather than promote communication and knowledge sharing. 
Clusters will rarely remain static - rather, they may grow in complexity or simplicity over time in response to internal and external dynamics.

Washington State's Environmental Hearings Office ("EHO") provides a good case study as to how a cluster model might evolve over time. Prior to reforms put into action in July 2011, the EHO housed a collection of five regulatory appeals boards dealing mainly with environmental controls and permits: Pollution Control Hearings, Shorelines Hearings, Forest Practices Appeals, Hydraulic Appeals, and Environmental and Land Use Hearings. Together, these boards heard appeals from regulatory orders and decisions made by the Department of Ecology, the Department of Natural Resources, by local governments and by other agencies as provided by law. The Boards derived their jurisdiction from different governing statutes and designed their own practices and procedures. However, the boards were co-located, members of some boards were available to be cross-appointed between tribunals, and the overall structure of EHO admitted a degree of administrative and logistical integration.

EHO's original structure provided for a "level field” on which each tribunal enjoyed — at least, formally — an equal position within the organization. This idea of formal equality supports the overall purpose of a cluster in which tribunals retain and cultivate their own areas of expertise, while promoting shared knowledge and cross-fertilization between each unit. But the formal equality between tribunals within the cluster might also mask informal or operational hierarchies that create significant distinctions in the roles and influence of different tribunals. EHO's experience in this regard is instructive. While that cluster was formally composed of five different boards, it appears that the Pollution Control Hearings Board (PCHB) was by far the most prominent tribunal within the cluster. The PCHB heard the largest proportion of cases coming to the EHO, its chair also sat as the head of the Shorelines Hearing Board, and he or she was the de facto director of the cluster's administrative operations, although there is no common chair on the adjudicative side. 
Similar kinds of informal dynamics may influence the outcomes of possible structural reforms discussed in Part III, below. For example, shared practices and an organizational culture that promotes active input from members of each tribunal in the cluster may be aimed creating greater equality between tribunals.

State legislative changes enacted in March 2010 laid the groundwork to reorganize Washington's system under a new cluster-type arrangement called the Environment and Land Use Hearings Office (ELUHO). ${ }^{69}$ The new ELUHO is composed of two departments dealing with land use and environmental hearings respectively. ${ }^{70} \mathrm{~A}$ preliminary question about the evolution from EHO to ELUHO is whether the environment and land sub-groupings will be largely formal organizing concepts or whether this arrangement will have significant practical implications for operating the cluster. The enabling legislation for the new cluster leaves it open as to whether the environment boards will have a common chair or individual chairs. It appears that a Chair responsible for the operation of the cluster as a whole will be appointed from the membership of either the land or environment sections, but that this Chair will not be cross-appointed to sit on tribunals for both sections. Inevitably, this model raises the spectre of competing visions for the mandate of the cluster - if a Chair from an environmental background is selected, will that suggest to the land use tribunal community that a particular substantive approach will dominate the cluster? In the case of ELTO,

\footnotetext{
69 Environmental and Land Use Hearings Boards - Consolidation, Substitute House Bill 2935, Ch 210, 61st Leg (2010). For a summary of this legislation, see Final Bill Report SHB 2135 (State of Washington 2010) <http://apps.leg.wa.gov/documents/billdocs/2009-10/Pdf/Bill\%20Reports/House\%20Final/2935S\%20HBR\%20FBR\%2010.pdf> accessed 22 November 2011.

${ }^{70}$ Before the July 1 reforms, a separate body composed of three regional Growth Management Boards dealt exclusively with land use and planning appeals in Washington under the State's Growth Management Act. The Land Use section of the ELUHO is composed solely of a re-designed Growth Management Hearings Board, which combines the three regional boards into a single seven-member body. The Environmental section includes two separate boards: a Pollution Control Hearings Board (which carries the workload of the previous Forest Practices and Hydraulics Boards) and a Shorelines Hearings Board. A first stage of reforms amalgamating the environmental boards took place in 2010, followed by the formal creation of the ELUHO in 2011.
} 
Ontario's environment and land tribunal cluster, it is significant that the first Executive Chair was chosen from a background that was in neither the environmental or land use fields. ${ }^{71}$

Washington's ongoing experience with tribunal reforms may offer a good opportunity to track the evolution of a cluster model going forward. As we discussed in Part I, a key aspect of tribunal clusters is their flexibility to adapt to changing needs and circumstances. ELUHO's recent round of restructuring offers a good illustration of how such clusters might change over time, and underscores the opportunity for further inquiry into the factors that motivate or influence these dynamics and their impact on access to justice for users.

\section{Amalgamation}

A third model illustrates the fluid boundary between tribunal clusters and more fully integrated amalgams or "super tribunals". Research into the actual structure and operation of these so-called super tribunals demonstrates that there is often no clear distinction between a single amalgamated tribunal with divisional sub-groupings or lists and a cluster of related tribunals that retain important aspects of their distinct mandates within the overall structure. ${ }^{72}$ The existing literature on tribunal reform might be criticized for obscuring this distinction by focusing almost explicitly on the concept of amalgamation, while ignoring contrasting or alternative concepts of clustering, even where the later would seem to be a more accurate label of the actual operation of the organization. Nonetheless, as we explain below, tribunal clusters can still draw important lessons from this body of work. In this section we draw on two examples from Australia to help illustrate how amalgamated tribunals can differ

\footnotetext{
${ }^{71}$ Michael Gottheil, the first Executive Chair (2009-2011) was Chair of the Ontario Human Rights Tribunal at the time he was appointed. Subsequently, in 2011, he was appointed to be the Executive Chair of Social Justice Tribunals Ontario, which includes the Human Rights Tribunal.

72 John Hopkins, 'Order From Chaos? Tribunal Reform in New Zealand' (2009) 2 Journal of the Australasian Law Teachers Association 47, 52 (criticizing this aspect of proposed reforms in New Zealand as 'a convoluted structure in the name of un-achievable unity'). These 'super tribunals' have also been labeled 'judicially-led amalgams' because they are commonly headed by a presiding judge, see Gabriel Fleming, 'Tribunals in Australia: How to Achieve Independence' in Robin Creyke (ed), Tribunals in the Common Law World (Federation Press 2008) 91.
} 
dramatically from each other in practice, as we set the stage to apply insights derived from research on Australia's super tribunals in Part III.

The Victorian Civil and Administrative Tribunal (VCAT and the New South Wales Administrative Decisions Tribunal (ADT) were created as State-level administrative bodies within a year of each other in the late 1990's. On their face, both bodies are the result of system-wide attempts by their respective State governments to overhaul what was considered to be an ad hoc collection of specialist tribunals to create a single unified tribunal service, with a standard set of processes and a single public persona. The VCAT, however, is likely closer in organization to a complex cluster than a unified amalgamation. It is divided into three main divisions_-Civil, Administrative, and Human Rights—and each division is further sub-divided into subject matter lists. The core functions of the VCAT are defined under the VCAT Act, while the jurisdiction exercised by each list is conferred by portfolio legislation. The Civil and Human Rights Divisions operate as “court substitutes” to adjudicate claims that were previously the domain of the Victorian Supreme Court, while the Administrative Division handles the review of government decisions under a range of statutes. The Administrative and Civil Divisions share one registry staff, excluding the Residential Tenancy and Guardianship Lists, which are each serviced by their own registry. While registry staff are divided into teams that service each list individually, tribunal-wide managers retain the flexibility to borrow staff from other areas according to workflow demands. $^{73}$

The President of the VCAT is a Judge of the Supreme Court. Individuals with legal qualifications dominate the VCAT's membership, and each member is appointed for a fiveyear fixed-term. Well over half of the VCAT's members are cross-appointed to more than

\footnotetext{
73 Justice Stuart Morris, 'The Emergence of Administrative Tribunals in Victoria' (Annual General Meeting of the Victorian Chapter of the Australian Institute of Administrative Law, Melbourne, 2003) <http://www.austlii.org/au/journals/VicJSchol/2003/4.pdf> accessed 22 November 2011.
} 
one list. The Tribunal has discretion to regulate its own procedures, making it possible to adapt these to specific proceedings and the requirements of individual Lists. For example, the Guardianship List operates on an informal, inquisitorial basis, while complex tax matters are adjudicated in an adversarial manner, usually involving legal representatives. The VCAT's flexibility to design its own procedures also allows it to implement some uniform operating procedures across the tribunal as a whole in order to promote shared approaches in some areas. $^{74}$

Compared to the VCAT, the ADT retains something of a dual personality as both a closely unified amalgam and a disjointed organization within which its division retain separate and distinct memberships and procedures. In many respects, the overall organization of the ADT is closer to a unified amalgam than a tribunal cluster. Much of the ADT's work takes place within the General Division, which includes claims from a wide range of subject matters. The ADT also maintains a central registry responsible for the tribunal as a whole, and its enabling legislation offers relatively few opportunities to adapt tribunal-wide procedures to different divisions and circumstances. But in other respects, the ADT resembles a loose collection of tribunals and divisions that operate in isolated spheres of jurisdiction and practice. Divisional units such as the Community Services (child services and adoption regulations) and the Retail Leases Divisions, retain the distinctive identities of their previously independent tribunals. Cross-appointments between the ADT divisions are infrequent and certainly less common compared to the VCAT. Many of the current fragmentation problems at the ADT have been traced back to this lack of cross-appointments and shared knowledge. ${ }^{75}$

In the end, semantic distinctions between broad-scale and generic tribunal clusters like VCAT and unified, or sometimes fragmented, bodies such as ADT are much less

\footnotetext{
74 Bacon (n 67) 106.

75 ibid 98.
} 
significant than the lessons which can be gleaned from studying the implications that flow from their various structural and procedural differences. The purpose of Part III is to unpack these various structural components of tribunal clusters. 


\section{Part III: Lessons \& Next Steps}

A review of the existing literature on tribunal reform internationally reveals that very little work has been done that evaluates 'best practices’ applicable to the cluster concepteither on its own or in comparison to other reform options. In other words, while it is interesting and worthwhile to compare reform models, in the absence of a comprehensive comparative literature that evaluates various models, is there a basis to prefer one over another? The academic literature which exists may be helpful in this regard. For example, in her doctoral thesis on amalgamating administrative tribunals, Rachel Bacon discusses specific outcomes of structural change in Australia over several key features for tribunal reform. Bacon’s project gathers lessons from her fieldwork, including first-person interviews of tribunal members and participants, to compare reform outcomes at the Victoria Civil and Administrative Tribunal (VCAT) and the Administrative Decisions Tribunal (ADT) in New South Wales. The following discussion attempts to translate relevant insights from this project into useful lessons for tribunal clusters in Ontario.

At the outset we can identify a number of general components that are likely to determine the ultimate character of a particular cluster arrangement. In its 2008 study on tribunal reform, the New Zealand Law Commission identified four basic components of cluster models, including: shared administrative support and services, shared membership (i.e. cross-appointed adjudicators), a common approach to procedures, and a cohesive overall leadership of the cluster. ${ }^{76}$ At least one additional feature might be added to this list. Physical co-location is very likely to be a feature of cluster arrangements. Indeed, co-location, as in ELTO’s case, may precede a more formal reorganization of tribunals into a cluster. But additional aspects of the cluster's physical space are also relevant, including office-space geography and the inclusions of shared spaces to increase membership interaction.

76 New Zealand Law Commission, Tribunal Reform (n 15) 54. 
We also note two further components of tribunal clusters that are not discussed in detail below, but which we flag for future research: (i) educational mechanisms for crosstraining members who sit on different tribunal within the cluster (as a means of enhancing quality, sharing experience, and developing a shared administrative culture) and (ii) the appointments process by which tribunal members are selected in the first place (so that the needs of the cluster, rather than its constitutive tribunals, may come to guide the process, including a commitment to transparent criteria, an emphasis on cross-appointment or lateral expertise, and an optimal balance of skills and backgrounds).

At a more general level, we assume that tribunal clusters will aim to cultivate a shared organizational culture, which might include an overarching mission/vision statement and common standards of excellence for tribunals within the group. The accountability documents now required under Tribunals Act in Ontario require each cluster to develop and make public service standards, publish an MOU with the Government, an annual report and a variety of ethics documents (conflict of interest codes, etc). ${ }^{77}$

A shared organizational culture will necessarily be shaped by and interrelated to other aspects of the cluster, such as the presence of a strong unified leadership and knowledge and information sharing between members. As Bacon observes, "features such as the level of interaction between members are both a manifestation and an underlying cause of the organizational culture within an amalgamated tribunal. This indicates that, far from being an inexorable given, organizational culture is something that, to some extent, can be controlled and engineered with positive effect." 78

Overall, Bacon's study concludes that the VCAT had been more successful at capitalizing on structural and procedural reforms to implement new mechanisms that improve access to justice compared to the ADT in New South Wales. The ADT had devolved into

\footnotetext{
${ }^{77}$ Jacobs (n 3).

78 Bacon (n 67) 296.
} 
what Bacon calls a “disjunctive institutional culture”, in which relatively disconnected parts of the organization operate at varying levels of formality, make arbitrary decisions about workload distribution and case-assignments to members, and have little or no adherence to a common vision for the organization as a whole. Despite the fact that the ADT appears to be organized more closely along the lines of a unified structure, the lines between previously independent tribunals often remain rigid barriers to knowledge transfer and the development of procedural innovations. ${ }^{79}$ By contrast, some of the benefits that Bacon observes from VCAT’s experience are: increased consistency in decision-making where members interact frequently to share knowledge and ideas; increased member and staff satisfaction, leading to better productivity; a more functional organization overall, adherence to a common set of values and shared aims; and an improved public profile for all tribunals or units within the organization, leading to increased independence from government and greater legitimacy in the public view.

\section{Shared rules, procedures and practices}

One way to measure the effectiveness of tribunal clustering for streamlining and improving cluster-wide procedures is to track the diffusion of specific practices within the cluster. Bacon uses the example of how Alternative Dispute Resolution (ADR) techniques have been adopted and applied within different VCAT Lists following the initial amalgamation. ${ }^{80}$ Particular divisions, such as the Planning List, which had previously used mediation practices infrequently saw a dramatic increase in the use of mediation after the VCAT was formed.

Bacon attributes the spread in mediation practice at VCAT to at least three causes. First, informal member communications were a main source of diffusion, linked to increased

\footnotetext{
79 ibid 308.

80 ibid 291.
} 
opportunities for members to interaction. ${ }^{81}$ Second, the VCAT’s leadership designed a periodic mediation newsletter to formalize some aspects of information sharing. Third, the VCAT appointed a Principle Mediator with a mandate for promoting the use of mediation throughout the organization, such as by organizing meetings and information sessions and inviting guest speakers to present to the membership.

The "spread" of these types of practices is a good example of how the idea of institutional memory inherent to the cluster concept can be used to promote positive reforms. For example, those tribunals coming into the cluster with a strong foundation in mediation practices can be tapped as a primary resource for promoting similar practices throughout the cluster. This feature suggests important benefits in the context of Ontario, where ADR practices tend to vary widely between tribunals.

\section{Shared membership and cross appointments}

Bacon's research finds at least two benefits of cross-appointing members between tribunal lists or divisions. The primary benefit was that cross-appointments created a means of breaking down some of the cultural barriers between separate subject-matter divisions by encouraging members to share knowledge, be open to new learning, and actively participate in the process of cultural change. The VCAT and ADT diverged widely on this feature, with cross-appointments being far more common in the VCAT. Bacon attributes much of the VCAT’s success to innovations in cross-appointing members. ${ }^{82}$

Field interviews with tribunal members indicated that changes on this front started small and grew gradually as new norms start to emerge. At the initial stage, crossappointments may simply lead to a greater recognition and comprehension of areas of overlap between units (i.e. tribunals within a cluster). For example, after VCAT members were crossappointed to the Guardianship List, these members began to quickly identify guardianship

\footnotetext{
${ }^{81}$ See our discussion of physical co-location and office geography in Part II, above.

82 Bacon (n 67) 287.
} 
issues in hearings on matters from different lists, particularly when dealing with problems faced by elderly people and people with disabilities in areas such as residential tenancies. Recognition was then followed, over time, with attempts on behalf of members to provide active assistance or direction for those with issues or problems that fell across two or more Lists.

A secondary benefit of cross-appointments is that they likely create better incentives to attract high-quality tribunal members. Bacon reports that the ability to sit as a crossappointed member increased these adjudicators' job satisfaction and contributed to improved career opportunities. $^{83}$

Issues related to full versus part time membership are also relevant here. Where a main objective of clustering is to share knowledge and effect cultural change across constituent tribunals, Bacon's findings indicate that these processes may be facilitated by more full time as opposed to part time members. The reasons given by members at VCAT and ADT are relatively straightforward. Full time members will increase the ability of the membership overall to develop and retain corporate knowledge because they are more actively involved in the day-to-day works of the cluster. The increased physical presence of full time members also makes it easier to organize member training and meetings, and creates greater opportunities for informal exchanges between individuals.

There can also be negative impacts, however, from decreasing the number of parttime members. The main challenge flagged in Bacon's research was that full time members in highly specialized areas might find it more difficult to retain their specialized expertise and skills in that field, given that they are unable to be actively involved in actual practice. ${ }^{84}$ In professional areas such as engineering and land use planning, this could result in a growing

83 ibid 287.

84 ibid 286. 
disconnect between full time members' knowledge/experience and the realities faced by the tribunals’ constituencies.

\section{Shared administrative support and services}

The VCAT and the ADT have apparently been equally successful at developing shared administrative services to suit their particular needs. But notably, positive outcomes such as improved efficiency, better staff training and development, and greater flexibility in mobilizing staff and resources to meet fluctuating workloads appear to be the result of both convergence and divergence at the administrative level.

On the one hand, trends at both the VCAT and ADT toward case-based management systems common to all sections or lists within the tribunals represent a focus on "multiskilling” for individual staff members. This approach emphasizes exposing individuals to a range of experiences on all aspects of a case, from beginning to end. On the other hand, the VCAT has retained some specialized administrative processes necessary to account for significant difference between Lists. For example the VCAT has maintained two parallel electronic case management systems — one for the Residential Tenancies List and one for the rest of the Tribunal. The reason for this distinction is the very high caseload of the Residential Tenancies List, which handles more than 70,000 applications per year. ${ }^{85}$

It is, of course, not necessary to have a formal cluster in order to realize these kinds of administrative efficiencies. Ontario’s Health Boards (the Health Professions Appeal and Review Board and the Health Services Appeal and Review Board) are not in a cluster but are supported by a shared secretariat through the Ministry of Health.

\section{Leadership}

A main issue related to tribunal cluster leadership is the nature and degree of authority over each of the constituent tribunals. In tribunal clusters, central leadership will likely be the

\footnotetext{
85 ibid 276-277.
} 
crucial pivot point in balancing between the cohesion of distinct sub-cultures and fostering the distinctiveness of constituent tribunals. Contrasting experiences at the VCAT and the ADT in this respect serve to illustrate the importance of strong leadership to make the cluster model successful. The VCAT's original president, a Supreme Court judge, has been credited with playing a central role in the organization's success. Bacon attributes this result to the VCAT president's personal commitment and vision, but also to the broad scope of discretion afforded to the president to shape the tribunal's procedures and other structural features in response to demands of the tribunal's users. ${ }^{86}$ By comparison, the ADT’s leader-similarly a judicial officer—was much more severely constrained in making important decisions about procedure and the structure of the ADT itself following amalgamation. For example, the ADT president held very limited power to cross-appoint members between divisions. This resulted in weak cohesion between the previous tribunals and severely curtailed the organization's ability to formulate a common vision and standards.

Challenges facing the leadership of many tribunal clusters may of course be even greater than those recognized in Bacon's study of the VCAT and the ADT, both of which have been designed in a detailed way to centralize decision-making power around a core executive. The scope of reforms in these jurisdictions, as well as the lens and language of tribunal amalgamation, create a default orientation toward strong leadership. Indeed, at first, the only concrete reality which makes a cluster a cluster may be the appointment of an Executive Chair (Social Justice Tribunals Ontario may be an example of this phenomenon). The nature of leadership roles within a cluster will also depend on the degree to which an Executive Chair is significantly involved in the administration of the tribunals, and on the possibilities for associate chairs of each tribunal to take on aspects of corporate and

86 ibid 316-318. 
jurisprudential leadership. ${ }^{87}$ For example, in Ontario the Tribunals Act permits the appointment of associate chairs, but does not make them mandatory, implying that the statute does not necessarily predetermine the particular roles of these leadership positions, where they exist, within the cluster. The leadership structure of these clusters will need to reflect evolving administrative and jurisprudential demands, both of the cluster as a whole and of particular tribunals, as they take shape.

To conclude, in the search for best practices, the experience of jurisdictions such as Australia provides tangible direction. Such best practices include:

- Shared rules, procedures and practices such as mediation/ADR;

- Shared administrative and support services, as well as physical co-location;

- Cross-appointments and the development of a common administrative culture;

- Strong, cohesive leadership of the organization.

Given that structural reforms tend to fall along a spectrum (from co-location to tribunal clusters to amalgamation), policy makers should expect that opportunities to learn from experiences in other jurisdictions will continue to arise, even where reform strategies take on different forms. For example, recent changes in the UK, discussed above, may provide yet another comparative Commonwealth model that tribunal clusters can triangulate with as clusters continue to evolve.

We turn now to the conclusion and move from a comparative and empirical analysis of cluster realities on the ground to some preliminary normative reflections on where the evolution of clusters ought to head in Ontario, Canada more broadly, and elsewhere.

\footnotetext{
87 See Justice Murray Kellam, 'Developments in Administrative Tribunals in the Last Two Years’ (2001) 29 Federal Law Review 427.
} 


\section{Conclusions}

The question Ontario’s administrative justice and government communities now wrestles with is: 'Why clusters?'

The legislation containing the power to create such clusters, the Tribunals Act, is silent on their purpose. This silence is puzzling. Some clusters may be justified by shared subject matter (such as ELTO), while others may be justified by common qualities among parties before a cluster (such as the rights seekers involved in the SJTO), but neither cluster was handed a mandate in which this rationale, or any rationale, was made apparent.

If you take the problem with administrative justice to be fragmentation, a lack of accessibility, duplication of resources, complexity of mandates and rules, and the lack of structural protections of independence or requirements of accountability, then clusters seem a half-measure at best. Why not bring all adjudicative tribunals together into a single amalgamated structure with different subject-matter sub-divisions, as in the UK? Clusters appear to mitigate rather than solve the problem of tribunals being caught up in ministerial silos, unable to coordinate, learn from each other or engage in economies of scale with respect to accessibility initiatives (like a common pool for translation and interpretation services).

The very existence of a cluster suggests an ambivalence - big is better but not too big! There is, indeed, a quintessentially Canadian dimension to the half-way house of clusters. While clusters are difficult to defend against ideological purists, they reflect the kind of principled pragmatism that has fueled the development of administrative justice in Canada.

The rhetoric surrounding the cluster initiative has cast it as a modernizing project. But the very notion of modernizing suggests a process rather than an end point. While system coherence is a central goal of structural change, it may be overly optimistic to think that we can achieve that goal with a single sweeping set of reforms. Different tribunals and their 
groups of users may have different needs at different times, and in our view some degree of flexibility to meet these varying needs is necessary.

We believe that it is impossible to discuss the risks and benefits of tribunal clusters in a normative vacuum. A coherent and coordinated system of administrative justice is better able to deliver access to justice, public accountability and the fulfillment of statutory and policy objectives. It is for this reason that, in our view, clusters represent an important and positive first step, rather than a destination. We acknowledge that this is choosing to see the glass as half-full. Once clusters are in existence, however, if further evolution does not come, all too soon, the glass may come to appear half empty! 